\title{
Nanoscale Process
}

National Cancer Institute

\section{Source}

National Cancer Institute. Nanoscale Process. NCI Thesaurus. Code C62307.

The methods necessary to engineer well-understood nanoscale phenomena into technology. 